\title{
Phosphate Solubilizing Bacteria and Fungi Isolated from Rubber (Hevea brasiliensis) Root Rhizosphere, Their Biofilm Formation and Phosphate Solubilizing Abilities
}

\author{
Hettiarachchi R.P. ${ }^{1 *}$, Dharmakeerthi R.S. ${ }^{1}$, Seneviratne G. ${ }^{2}$, Jayakody A.N. ${ }^{3}$, \\ De Silva E. ${ }^{1}$, Gunathilake T. ${ }^{1}$ and Thewarapperuma A. ${ }^{1}$ \\ ${ }^{1}$ Rubber Research Institute, Agalawatta, Sri Lanka \\ ${ }^{2}$ Institute of Fundametal Studies, Sri Lanka \\ ${ }^{3}$ Department of Soil Science, University of Peradeniya, Peradeniya, Sri Lanka \\ *rasikarri@yahoo.com
}

\begin{abstract}
The ability of some soil microorganisms and their biofilm combinations to convert insoluble forms of phosphorus to an accessible form is an important trait associated with plant $\mathrm{P}$ nutrition. The phosphorus solubilizing potential of bacteria and fungi isolated from Hevea rhizosphere and their effective biofilm communities were evaluated using solid and liquid media under in vitro conditions. Phosphate solubilization ability of them were tested on calcium phosphate media by analysing the soluble $\mathrm{P}$ content after incubation at $28 \pm 2{ }^{\circ} \mathrm{C}$. Out of the microbial isolates, 10 bacterial colonies and one fungal colony formed haloes (clear zones) around the isolate growing on solid media containing calcium phosphate as the sole phosphate source. Spectrophotometric quantification of phosphorus solubilization in the liquid media showed that the ten bacterial isolates, and ten fungal isolates solubilized insoluble calcium phosphate in to the liquid media in the range of $200-450$ and $200-300$ $\mathrm{mg} \mathrm{P} \mathrm{L}{ }^{-1}$ respectively. Biofilm showed significantly higher $\mathrm{P}$ solubilization $(853.3 \pm 25.17 \mathrm{mg}$ $\mathrm{P} \mathrm{L}^{-1}$ ) than their bacteria and fungi counterparts alone. Phosphate solubilization of bacteria, fungi and their biofilm could be attributed to the secretion of organic acids. A significant drop in the $\mathrm{pH}$ of the broth media (4.7 to 5.6) compared to the $\mathrm{pH}$ of the control treatment (6.8-7.0) was observed. $\mathrm{pH}$ change in the media could be due to secretion of organic acids by microorganisms and/or utilisation of compounds in the broth media. Although there was a significant synergistic effect on $\mathrm{P}$ solubilization due to biofilm formation, $\mathrm{pH}$ in the liquid media of their mono cultures and biofilm were not significantly different. This observation warrants further investigation.
\end{abstract}

Keywords: Hevea brasiliensis, Rhizosphere microbes, Biofilm, Biosolubilization of phosphorus 